\title{
Acute Effects of Self-selected Music Intervention on Recovery of Autonomic Functions and Anxiety after Submaximal Intensity of Short-Term Cycling
}

\section{Efectos agudos de la intervención musical autoseleccionada en la recuperación de las funciones autónomas y la ansiedad después de la intensidad submáxima del ciclismo a corto plazo}

\author{
Iao Ka-Lok' ${ }^{1}$, Yung-Sheng Chen ${ }^{1 *}$, , Wan-An Lu ${ }^{2}$, Pedro Bezerra ${ }^{3,4}$ \\ 1 Department of Exercise and Health Sciences, University of Taipei, Taipei 11153, Taiwan \\ 2 Institute of Cultural Asset and Reinvention, Fo-Guang University, Yilan 26247, Taiwan; wanan.lu@msa.hinet.net \\ 3 Escola Superior de Desporto e Lazer, Instituto Politécnico de Viana do Castelo, Melgaço 4960-320, Portugal \\ 4 The Research Centre in Sports Sciences, Health Sciences and Human Development, Vila Real 5001-801, Portugal \\ * Correspondence: yschen@utaipei.edu.tw; Tel.: +886 22871-8288\#6405
}

Received: 12/03/2020; Accepted: 01/05/2020; Published: 03/07/2020

\begin{abstract}
:
Background: Music intervention is considered as an optimal modality to improve exercise motivation, exercise performance, and endurance capacity. The aim of this study is to investigate the acute effects of self-selected music intervention on post-exercise heart rate (HR), HR variability (HRV) and anxiety after a submaximal intensity of cycling exercise. Methods: Fifty-two healthy adults (males: $n=24$, age: $20.6 \pm 2$ yrs; female: $n=28,21.8 \pm 2.1$ yrs) were voluntarily participated this study. A counter-balanced design was used to examine submaximal intensity of cycling exercise with non-music or self-selected music trials at least 48 hours apart. Participants first visit the laboratory to determine individual self-selected music and to complete an incremental exercise test until HR response researched to $80 \%$ of heart rate reserve (HRreserve). The $80 \%$ HRreserve was used to control the exercise intensity during a subsequent 10-minute stationary cycling exercise. At the beginning of experiment, the participants performed a 5-min cycling warm-up exercise with self-pace. Afterwards, the participants rested in a sitting position for 5-min and then performed 10-min cycling exercise with intensity of $80 \%$ HRreserve. After the cycling exercise, 5-min HR recovery (HRR) and 10-min HRV was measured in a sitting position for 15-min. A situational anxiety mass scale (STAI-S) was used immediately after the cycling exercise. Music intervention was applied during 15-min post-exercise recovery. Results: The exercise HR and post-exercise HRV showed no significant differences between self-selected music trial and non-music trial in both groups. In self-selected music trial, HRR was significantly faster after the self-selected music trial than that of non-music trial in female. In addition, the STAI-S scores were significantly lower in the self-selected music trial than that of non-music trial in both groups. Conclusion: Self-selected music intervention can improve HRR in healthy female. Consideration to implement a self-selected music intervention after submaximal intensity of stationary cycling exercise to reduce post-exercise anxiety in male and female is warrant.
\end{abstract}

Keywords: Music intervention, heart rate recovery, heart rate variability, submaximal intensity, cycling exercise 


\section{Resumen:}

Antecedentes: la intervención musical se considera una modalidad óptima para mejorar la motivación del ejercicio, el rendimiento del ejercicio y la capacidad de resistencia. El objetivo de este estudio es investigar los efectos agudos de la intervención musical autoseleccionada sobre la frecuencia cardíaca (FC) posterior al ejercicio, la variabilidad de la FC (VFC) y la ansiedad después de una intensidad submáxima del ejercicio en bicicleta. Métodos: Cincuenta y dos adultos sanos (hombres: $\mathrm{n}=24$, edad: $20.6 \pm 2$ años; mujeres: $\mathrm{n}=28,21.8 \pm 2.1$ años) participaron voluntariamente en este estudio. Se utilizó un diseño equilibrado para examinar la intensidad submáxima del ejercicio de ciclismo con ensayos musicales no musicales o autoseleccionados con al menos 48 horas de diferencia. Los participantes primero visitan el laboratorio para determinar la música individual seleccionada por ellos mismos y completar una prueba de ejercicio incremental hasta que la respuesta de FC investigue al $80 \%$ de la reserva de frecuencia cardíaca (HRreserve). El 80\% HRreserve se utilizó para controlar la intensidad del ejercicio durante un ejercicio de ciclismo estacionario de 10 minutos. Al comienzo del experimento, los participantes realizaron un ejercicio de calentamiento en bicicleta de 5 minutos con ritmo propio. Posteriormente, los participantes descansaron sentados durante 5 minutos y luego realizaron 10 minutos de ejercicio en bicicleta con una intensidad de reserva de HR del $80 \%$. Después del ejercicio de ciclismo, se midió la recuperación de la FC de 5 minutos (HRR) y la HRV de 10 minutos en una posición sentada durante 15 minutos. Se utilizó una escala de masa de ansiedad situacional (STAI-S) inmediatamente después del ejercicio de ciclismo. La intervención musical se aplicó durante 15 minutos después de la recuperación del ejercicio. Resultados: El HR de ejercicio y el HRV posterior al ejercicio no mostraron diferencias significativas entre el ensayo musical autoseleccionado y el ensayo no musical en ambos grupos. En la prueba musical autoseleccionada, la HRR fue significativamente más rápida después de la prueba musical autoseleccionada que la de la prueba no musical en mujeres. Además, las puntuaciones de STAI-S fueron significativamente más bajas en la prueba musical autoseleccionada que en la prueba no musical en ambos grupos. Conclusión: la intervención musical autoseleccionada puede mejorar la HRR en mujeres sanas. Se justifica la implementación de una intervención musical autoseleccionada después de la intensidad submáxima del ejercicio de ciclismo estacionario para reducir la ansiedad posterior al ejercicio en hombres y mujeres.

Palabras Claves: Intervención musical, recuperación de la frecuencia cardíaca, variabilidad de la frecuencia cardíaca, intensidad submáxima, ejercicio en bicicleta

\section{Introduction}

Music intervention is considered as an optimal modality to improve exercise motivation, exercise performance, and endurance capacity. It has been reported that music can change motor neural drive (Bigliassi, Karageorghis, Bishop, Nowicky, \& Wright, 2018), cardiovascular functions (Koelsch, \& Jäncke, 2015), perceptual and cognitive responses (Stork, Gibala, \& Martin, 2015). Moreover, music intervention could enhance aerobic (Atkinson, Wilson, \& Eubank, 2004) and anaerobic capacities (Ballmann, Maynard, Lafoon, Marshall, Williams, \& Rogers, 2019; Chtourou, Jarraya, Aloui, Hammouda, \& Souissi, 2012; Jarraya et al., 2012) during exercise. The music-related interventions are suggested as a useful tool to alter psychological responses and fatigue-related symptoms in association enhancing exercise performance and recovery status (Bigliassi, 2015; Karageorghis \& Priest, 2012ab).

It has been reported that implementation of music intervention either before or during exercise can improve exercise performance. Listen to preferable music before exercise optimize psychological and physiological performance during exercise. For example, Smirmaul, dos Santos, 
\& da Silva Neto (2015) showed that 5-min pre-exercise music intervention enhanced 200-m free style swimming performance and motivation. In addition, synchronized music intervention during exercise contributes to enhancement of exercise performance and psychometric conditions. For example, fast tempo music intervention $(130 \mathrm{bpm})$ during exercise can prolong high-intensity cycling exercise duration and acceleration of heart rate (HR) recovery (HRR) (Maddigan, Sullivan, Halperin, Basset, Behm, 2019). Empirical evidence also demonstrated positive benefits of synchronized music intervention while exercise on endurance capacity and exercise motivation (Atkinson et al., 2004; Terry, Karageorghis, Saha, \& Auria, 2012).

Exercise recovery is one of popular scheme to improve heath and exercise performance in athletic and physically active populations. However, information regarding effect of music intervention on post-exercise recovery has not been extensively understood. Post-exercise music intervention has been shown as an optimal tool to facilitate psychophysiological recovery after maximal intensity of cycling exercise (Karageorghis, Bruce, Pottratz, Stevens, Bigliassi, \& Hamer, 2018), repeated bouts of intense cycling exercise, and intense short-term running (Eliakim, Bodner, Eliakim, Nemet, \& Meckel, 2012; Eliakim, Bodner, Meckel, Nemet, \& Eliakim, 2013). To our knowledge, there is no information in the literature to discuss acute effects post-exercise music intervention on autonomic functions after submaximal intensity of cycling exercise and its manners regarding gender difference. This information is essential to general population who favourites to enjoy daily exercise in gym and home-based facilities. In light of above-mentioned, the purpose of this study was to investigate the acute effects of self-selected music intervention during recovery status on post-exercise HRR, HRV, and anxiety after a submaximal intensity of stationary cycling exercise. It was hypothesized that HRR and HRV indices would be significantly recovered faster and anxiety level would be reduced in self-selected music trial than that of controlled trial.

\section{Materials and Methods}

\section{Participants}

Fifty-two healthy university students voluntarily participated in this study (24 male and 28 female, Table 1). Inclusion criteria included 1) aged between 20-30 yrs, 2) current university students. Excluded criteria included 1) current neuromuscular injuries, 2) current cardiovascular diseases, and 3) current metabolic diseases. A physical condition status screening questionnaire was used to identify the physical status and contraindication to participation in this study. All participants were instructed to refrain from taking caffeine-containing substances and smoking within 2-h of the testing session, and were asked not to perform strenuous exercise activity for 24-h before the testing session. The participants underwent a familiarisation session before the experiment. This study was conducted in accordance with the Declaration of Helsinki.

Research design

Cross-over and randomized control design

Experimental procedure

The participants firstly visited the laboratory to familiarize the experimental procedure and undertook an incremental cycling test utile individual exercise HR approached to $80 \%$ of HR reserve (HRreserve). Participants' physical characteristics, and individual preference of self-selected music were also determined in the first visit. All participants wore comfortable sports clothes and 
shoes during the experiment. After 7 days, the participants conducted self-selected music trial and non-music trial in a randomized order at least 48-h apart. A computer-generated random number table (https://www.randomizer.org/) was generated to assign the experimental conditions. At the beginning of experiment, the participants sit on a comfortable chair for 5-min and measured resting HR. The participants then adjusted the seat height of the cycling ergometer to suit the participants and performed a 5-min cycling warm-up exercise with self-pace. Afterwards, the participants rested in a sitting position for 5-min and then performed 10-min cycling exercise with 60 revolutions of the crank per minute (rpm). The participants were instructed to increase the HR to target zone in $1 \mathrm{~min}$ and then maintained exercise intensity at $80 \%$ HRreserve throughout the cycling exercise. After the cycling exercise, 5-min HRR and 10-min HRV were measured in a sitting position. A situational anxiety mass scale (STAI-S) was measured immediately after the cycling exercise. The participants maintained sitting position and listen self-selected music for music trial while resting condition for non-music trial. Room temperature was controlled at $25^{\circ} \mathrm{C}$. All experiments were conducted between 7 a.m. to 1 p.m.

Submaximal intensity of incremental exercise test

The incremental exercise test was adapted from Michael et al's study (2016). Participants conducted the incremental exercise test on a stationary ergometer (Optibike Med 100, Ergoline, Germany) until $80 \%$ of HRreserve. The initial resistance was set at 50 watts while the participants maintained revaluation rate at $60 \mathrm{rpm}$. Another 25 watts of power output was added every 5 -min of cycling exercise utile $80 \%$ HRreserve was reached. Individual power output of cycling exercise at $80 \%$ HRreserve was determined for following music and non-music trials. The maximal HRreserve was determined by age-predicted maximal HR - resting HR (Karvonen, Kentala, \& Mustala, 1957).

Synchronized selected music intervention

The participants selected their favorite music for 15-min duration. The participants sit on a comfortable chair and maintain their posture during post-exercise recovery. Music was delivered via an earlobe (EX15AP, Sony, China) connected to a smart phone (IPhone 7, Apple, China). The category of self-selected music included classical, electronic, jazz, metal, rock, and pop. The tempo of self-selected music was defined as slow tempo music ( $<120 \mathrm{bpm})$ or fast tempo music (>120 bpm) (Karageorghis, Terry, \& Lane, 1999).

Heart rate and heart rate variability

The ECG signals were recorded for 15-min in a sitting position to evaluate HR and HRV modulations after cycling exercise. The assessment was performed in a quiet research room to obtain electrocardiographic (ECG) records (MP36, Biopac Inc., Goleta, CA, USA) via conventional lead II arrangement with a sampling rate of $1000 \mathrm{~Hz}$. The first 5-min ECG data were used to evaluate HRR while the 6-15 min ECG data were used to evaluate HRV. The ECG waveforms were then filtered using a commercial HRV analysis software (Premium version 3.2, Kubios, Kuopio, Finland) to calculate the HR and HRV indices. Strong artefact correction and smoothing priors set at 500 Lambda were used for HRV analysis. The mean RR (MeanRR), mean sum of the squared differences between RR (RMSSD) were calculated by using the standard formulae for time domain analysis. In addition, the power spectra of RR intervals were calculated by means of fast Fourier transformation for frequency domain analysis. The normalised power of low-frequency power (LF) and high-frequency power (HF) were used to calculate the powers of frequency bands in normalised units. The LF and HF ranges were set as $0.04-0.15 \mathrm{~Hz}$ and $0.15-0.4 \mathrm{~Hz}$, respectively. 
Nonlinear analyses of the Poincaré plot indices SD1 and SD2 were also performed to determine the nonlinear characteristics of HRV.

\section{Rating of perceived execution}

A conventional 15-point Borg scale was used to evaluate the rate of perceived exertion (RPE) (Borg, 1982). The minimal point is 6 indicated very very light exercise workload, whereas the maximal points is 20 indicated maximal exertion of exercise workload. The participants reported the rate of RPE every minute during 10-min cycling exercise.

STAI-S

A Chinese version of state-trait anxiety inventory-state (STAI-S) was used to assess anxiety after the cycling exercise. This questionnaire consisted of twenty statements to indicate the psychological status during the evaluation (Spielberger, 1970). Each statement has a 4-points Likert scale. First point indicates not at all whereas four point indicates very much so. The minimal score of the questionnaire is twenty; whereas the maximal score of the questionnaire is eighty. The lower STAI-S score indicates lower anxiety level, while higher STAI-S score indicated higher anxiety level. Data analyses

To measure the HRR (HRR30s, HRR60s, HRR120s, and HRR 300s) after the submaximal intensity of cycling exercise, the following formula was used:

$\mathrm{HRR}=$ difference between peak $\mathrm{HR}$ at exercise termination and HRR at the time point during recovery.

Statistical analyses

Descriptive data of the measured variables were presented as mean and standard deviations (mean $\pm \mathrm{SD}$ ). The normal distribution of study variables were examined with the Kolmogorov-Smirnov test. Three way repeated measurement of analysis of variance test (ANOVA) [Time (4) x condition (2) x gender (2)] was used to examine exercise HR, RPE, and HRR (HRR30s . HRR60s $、 H R R 120 s \cdot H R R 300 s)$. Another two way repeated measurement of analysis of variance test (ANOVA) [music (2) x gender (2)] was used to examine the HRV indices and STAI-S. When a significant main effect or an interaction is found, a post-hoc analysis with Bonferroni adjustment was conducted to identify significant differences between the values. An alpha value of $P \leq 0.05$ was set for significant differences between the means. All statistical analyses were performed by SPSS version 24.0 software for windows (IBM, Armonk, NY, USA).

\section{Results}

Physical characteristics of participants

Age, anthropometric profiles, individual $80 \%$ HR reserve during incremental exercise test, power

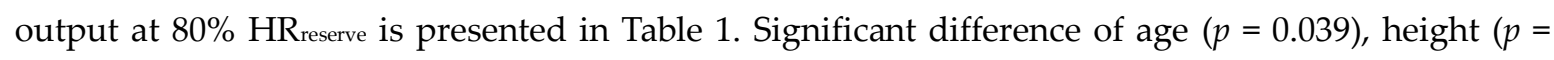
$0.001)$, body weight $(p=0.001)$, power output $(p=0.001)$, and $\mathrm{HR}_{\max }(p=0.039)$ were found between male and female participants. 
Table 1. Physical characteristics of the participants and exercise capacity during incremental exercise test.

\begin{tabular}{cc}
\hline Physical characteristics & Mean \pm Standard deviation $($ Male $=24$ / Female $=28)$ \\
\hline Age $(\mathbf{y r s})$ & $21.23 \pm 2.11(\mathrm{M}=20.58 \pm 2.00 ; \mathrm{F}=21.79 \pm 2.08)$ \\
Height $(\mathbf{c m})$ & $167.12 \pm 8.5(\mathrm{M}=174.25 \pm 4.93 ; \mathrm{F}=161.00 \pm 5.66)$ \\
Weight $(\mathbf{k g})$ & $62.73 \pm 12.49(\mathrm{M}=70.54 \pm 11.69 ; \mathrm{F}=56.04 \pm 8.81)$ \\
Rest heart rate (bpm) & $75.19 \pm 10.54(\mathrm{M}=73.88 \pm 9.90 ; \mathrm{F}=76.32 \pm 11.12)$ \\
$\mathbf{8 0}$ \% heart rate reserve (bpm) & $174.12 \pm 2.85(\mathrm{M}=174.42 \pm 2.62 ; \mathrm{F}=173.86 \pm 3.06)$ \\
Maximal heart rate (bpm) & $198.77 \pm 2.11(\mathrm{M}=199.42 \pm 2.00 ; \mathrm{F}=198.2 \pm 2.1)$ \\
Power output $(\mathbf{W})$ & $114.42 \pm 29.85(\mathrm{M}=139.58 \pm 19.39 ; \mathrm{F}=92.86 \pm 17.82)$ \\
\hline
\end{tabular}

Note: $\mathrm{M}=$ male; $\mathrm{F}=$ female

\section{Individual self-selected music intervention}

The results showed 9 male participants selected slow tempo music (rock $=1$ and pop $=8$ ) while 15 male participants selected fast tempo music (classical $=1$, electronic $=1$, jazz $=1$, and pop $=$ 12). In addition, 11 female participants selected slow tempo music (electronic $=1$ and pop $=10$ ) and 17 female participants selected fast tempo pop music (Table 2).

\section{Exercise heart rate and rate perceived of execution}

The results showed no time, condition, and gender interaction on exercise $\operatorname{HR}[F(9,450)=0.35$, $\left.p=0.809, \eta^{2}=0.012\right]$, time and condition interaction $\left[F(9,450)=0.761, p=0.653, \eta^{2}=0.015\right]$, and condition and gender interaction [ $\left.F(1,50)=2.886, p=0.096, \eta^{2}=0.055\right]$. There were time and gender interaction $\left[F(9,450)=5.682, p=0.001, \eta^{2}=0.102\right]$ and main effect of time $[F(9,450)=494.345, p=$ $\left.0.096, \eta^{2}=0.908\right]$ on exercise HR. The Bonferroni adjustment revealed significant difference among all exercise HR responses $(p=0.05)$.

For RPE, a main effect of time [ $\left.F(9,450)=18.030, p=0.001, \eta^{2}=0.265\right]$ was found. The post hoc comparison revealed significant difference among all RPE $(p=0.05)$, except a pairwise comparison between $9^{\text {th }}$ minute and $10^{\text {th }}$ minute $(p=1.00)$ (Figure 1$)$.

Table 2. Category of individual self-selected music intervention.

\begin{tabular}{|c|c|c|c|c|}
\hline \multirow[b]{2}{*}{ Category } & \multicolumn{2}{|c|}{ Male } & \multicolumn{2}{|c|}{ Female } \\
\hline & $\begin{array}{c}\text { Slow tempo } \\
(n=9)\end{array}$ & $\begin{array}{c}\text { Fast tempo } \\
(n=15)\end{array}$ & $\begin{array}{c}\text { Slow tempo } \\
(n=11)\end{array}$ & $\begin{array}{c}\text { Fast tempo } \\
\quad(n=17)\end{array}$ \\
\hline Classical & - & 1 & - & - \\
\hline Electronic & - & 1 & 1 & - \\
\hline Jazz & - & 1 & - & - \\
\hline Metal & - & - & - & - \\
\hline Rock & 1 & - & - & - \\
\hline Pop & 8 & 12 & 10 & 17 \\
\hline
\end{tabular}

Note: Slow tempo music frequency $<120 \mathrm{bpm}$; fast tempo music frequency $>120 \mathrm{bpm}$. 
Figure 1. Exercise heart rate and rating perceive of execution responses during 10-min cycling

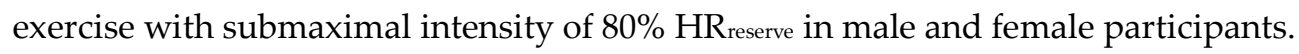
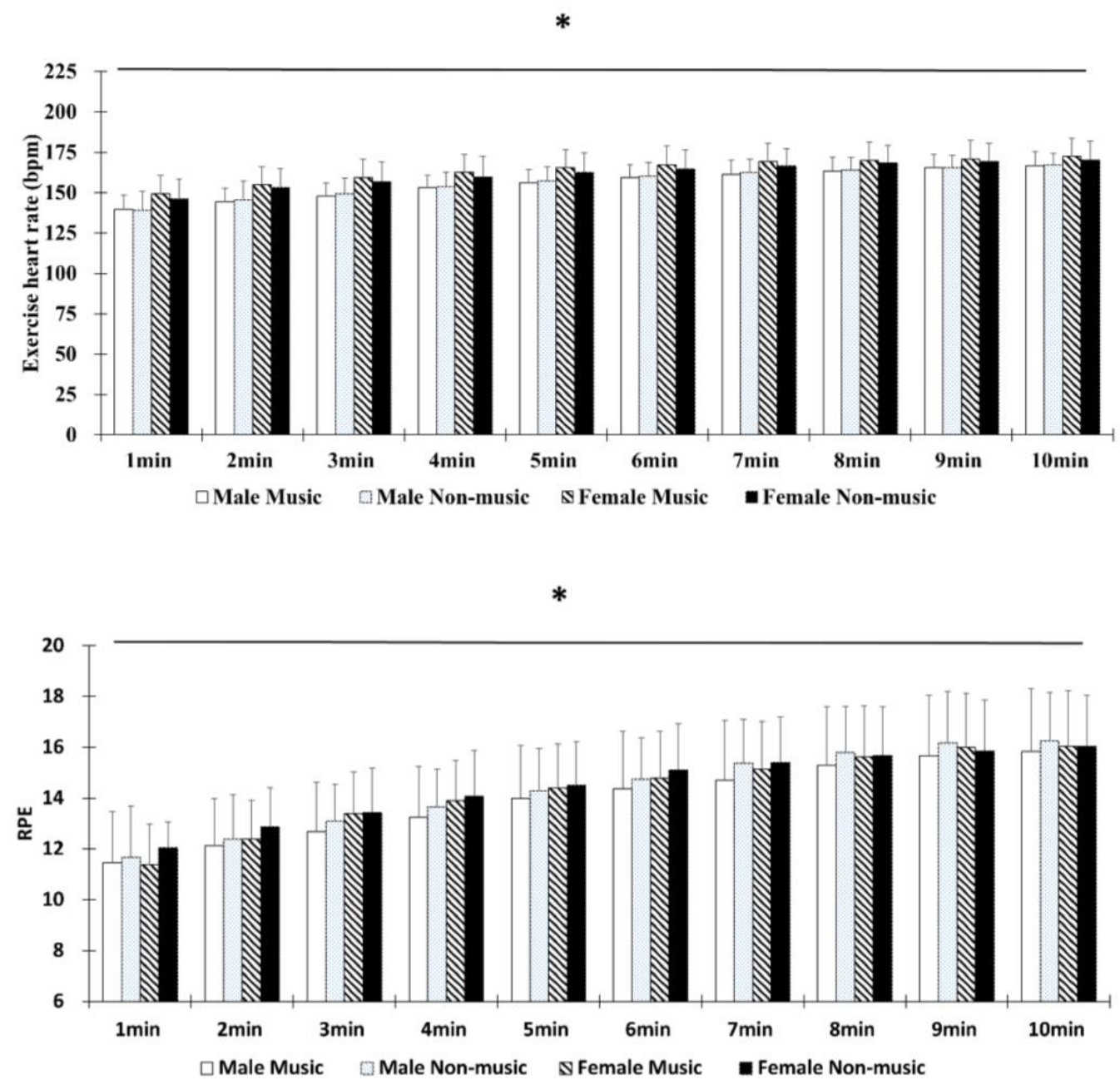

* Significant difference between time $(p<0.05)$.

Heart rate recovery

The results showed no time, condition, and gender interaction on $\operatorname{HRR}[F(3,150)=0.350, p=$ $\left.0.766, \eta^{2}=0.007\right]$. However, there were main effect on condition $\left[F(1,50)=12.450, p=0.001, \eta^{2}=\right.$ $0.199]$ and time $\left[F(1,50)=751.20, p<0.001, \eta^{2}=0.938\right]$. The post hoc analysis revealed no significant difference of HRR in male participants. However, significant condition difference of HRR was found in female participants $(p<0.001)$ (Figure 2). 
Figure 2. Post-exercise heart rate recovery (5-minutes) after muisc or non-music interventions in male and female participants.

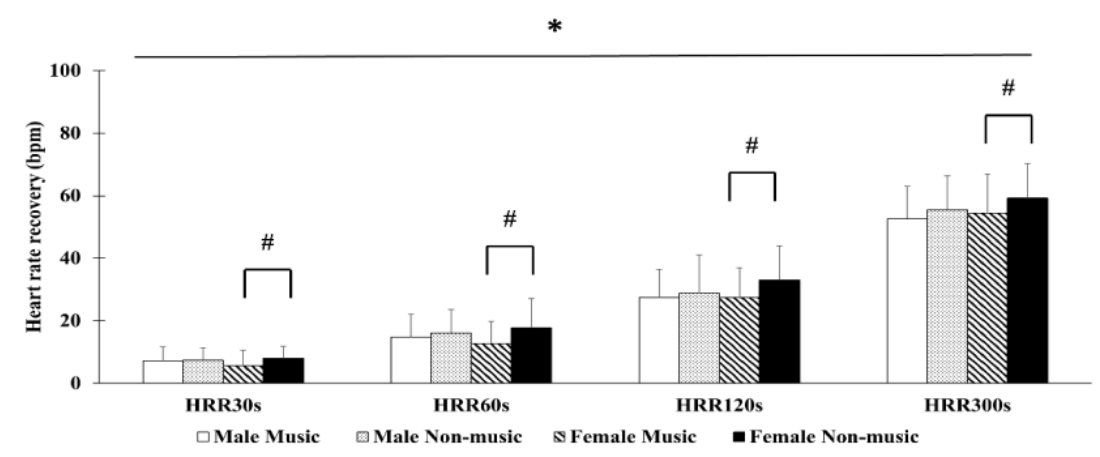

* Significant difference between time $(p<0.05)$. \# Significant difference between conditions $(p<$ $0.05)$.

Heart rate variability

The results showed no condition and gender interaction on $\operatorname{RMSSD}[F(1,50)=0.03, p=0.862$, $\left.\eta^{2}=0.001\right]$, Mean RR $\left[F(1,50)=0.137, p=0.713, \eta^{2}=0.003\right], \operatorname{LF}\left[F(1,50)=0.093, p=0.762, \eta^{2}=0.02\right]$, HF $\left[F(1,50)=1.381, p=0.246, \eta^{2}=0.003\right], \mathrm{LF} / \mathrm{HF}$ ratio $\left[F(1,50)=0.484, p=0.490, \eta^{2}=0.001\right]$, SD1 $\left[F(1,50)=1.380, p=0.245, \eta^{2}=0.027\right], \operatorname{SD} 2\left[F(1,50)=0.454, p=0.503, \eta^{2}=0.009\right]$, and SD2/SD1 ratio $\left[F(1,50)=1.140, p=0.737, \eta^{2}=0.002\right]$. There was main effect of condition on Mean RR $[F(1,50)=$ $\left.6.690, p=0.013, \eta^{2}=0.118\right]$ and main effect of gender on $\operatorname{LF}\left[F(1,50)=8.060, p=0.007, \eta^{2}=0.139\right]$. However, post hoc analysis showed no significant difference in all comparisons (Figure 3 and Figure 4).

Figure 3. Mean R-R interval during 5 minuites recovery after muisc or non-music interventions in male and female participants.

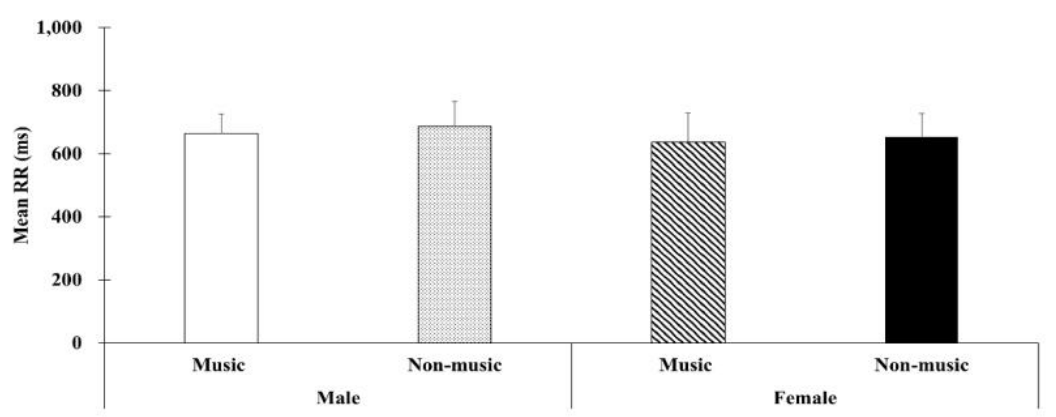


Figure 4. Mean sum of the squared differences between RR (RMSSD), normalised power of low-frequency power (LF), normalised power of high-frequency power (HF), LF/HF ratio, SD1, SD2, and SD2/ SD1 ratio during 5 minuites recovery after music or non-music trial in male and female participants.

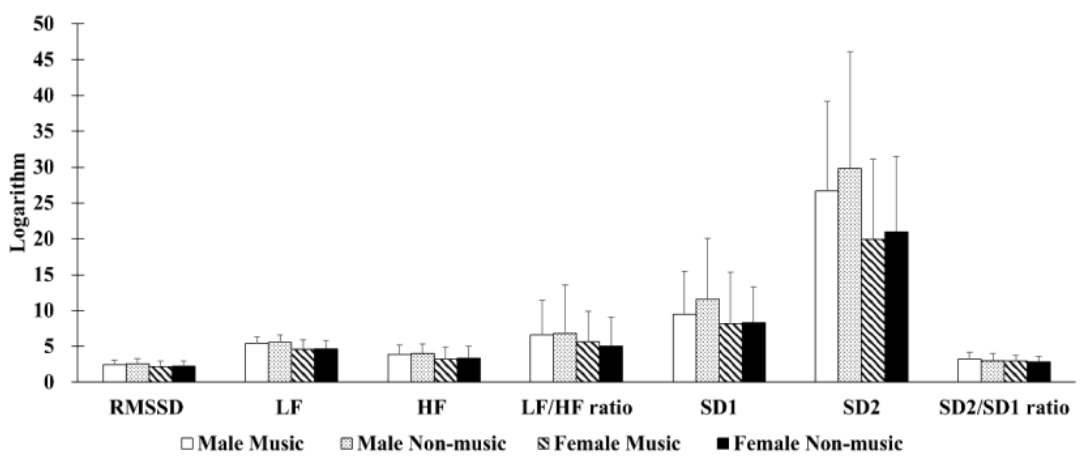

Note: data are presented as natural logarithm values.

\section{STAI-S}

The result showed no condition and gender interaction in STAI-S [ $F(1,50)=1.542, p=0.220, \eta^{2}$ $=0.030]$. However, main effect of condition on STAI-S was found $\left[F(1,50)=40.540, p<0.001, \eta^{2}=\right.$ 0.045]. The post hoc comparison revealed that STAI-S score was significant higher in non-music trial than that of music trial in male and female participants (male: non-music $=31.00 \pm 4.89$ vs music $=$ $26.96 \pm 5.37$; female: non-music $=34.07 \pm 8.25$ vs music $=28.07 \pm 5.42)$ (Figure 5).

Figure 5. The scores of state-trait anxiety inventory-state after music or non-music trial in male and female participants.

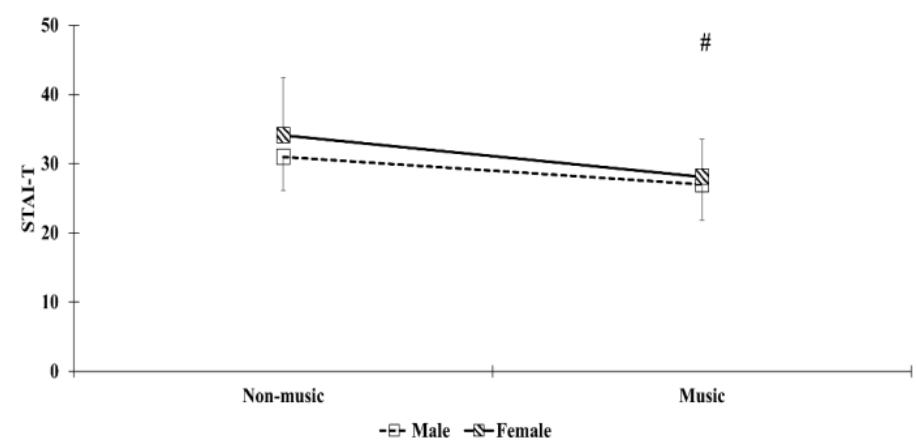

\# Significant difference between conditions $(p<0.05)$. 


\section{Discussion}

This was first study to report acute effect of self-selected music intervention on post-exercise $\mathrm{HR}, \mathrm{HRV}$, and anxiety after submaximal intensity of stationary cycling exercise. The primary fining of the study was that self-selected music significantly improved post-exercise HRR in healthy female adults after a submaximal intensity of 10-min cycling exercise. Moreover, post-exercise anxiety level was significantly reduced in healthy male and female participants when self-selected music was implemented.

The main purpose of this study was to examine the effect of self-preferable music intervention on HRR. Our study revealed that healthy female adults accelerated HRR during music trials than that of non-music trial whiles no condition effect was observed in healthy male adults. Indeed, information regarding post-excise music intervention on HRR is controversial. Eliakim et al. (2012) demonstrated that motivational music was unable to change the HRR but was able to alter blood lactate clearance and alleviated perceived execution during 15-min post-exercise recovery after 6-min running at speed of peak oxygen consumption. In contrast, listening slow tempo music fasted HRR after 20-min self-pace treadmill running (Lee, \& Kimmerly, 2016). Savitha, Mallikarjuna, and Rao (2010) reported that slow temp music intervention contributed to great recovery of pulse rate and blood pressure than that of fast tempo music and non-music condition. Also, Jones, Tiller, \& Karageorghis (2017) demonstrated fast tempo music intervention facilitated quick HRR and great feeling scale score during initial recovery periods of 3-min rest interval during $5 \times 5$-min repeated bouts of intense cycling exercise. Based these observations, it is difficult to provide solid evidence to discuss the findings. The possible explanation is that gender difference of autonomic activities under psychological stress (Kudielka Buske-Kirschbaum Hellhammer \& Kirschbaum, 2004). There was an empirical study to support that healthy women tends to reduce arousal level during recovery after maximal incremental cycling test (Karageorghis et al., 2018). Nevertheless, gender difference of HRR to response preferable music intervention after a submaximal intensity of cycling exercise was suggested in our study.

It is interesting to note that post-exercise self-selected music intervention cannot influence the rhythmic HR beats as indicated by HRV modulation in the present study. Our results were against a previous investigation showing significant difference of frequency domain HRV indices after 15-min light intensity of cycling exercise (Urakawa \& Yokoyama, 2005). Jia, Ogawa, Miura, Ito, \& Kohzuki (2016) suggested that cycling exercise with synchronized music intervention can increase parasympathetic reactivation after the exercise. However, Jia et al's and study implemented a cycling protocol at moderate intensity (around 13 of RPE) for 15-min duration that may undermined the true interpretation of autonomic recovery due to absence of time domain HRV indices in their study (Plews, Laursen, Stanley, Kilding, \& Buchheit, 2013). The underlying mechanisms to regulate the cardiac-autonomic activities need future studies to examine.

The present study showed that anxiety level was significantly reduced when self-selected music intervention was implemented after short-term submaximal intensity cycling exercise in health male and female adults. Krout (2007) reported that music intervention results in psychological relaxation, pleasure mood, and stress relief via limbic system of the brain and it-related neurological responses, consequently change in hormonal responses. Our finding was in agree with previous studies showing positive benefits of music on psychological responses before 
(Smirmaul, 2017), during (Atkinson et al., 2004; Jones et al., 2017), and after exercise (Karageorghis et al., 2018).

The present study revealed that post-exercise music intervention could improve psychological condition and HRR but not HRV. Based on the findings of this study, it is suggested to investigate acute effect of different types of music interventions (category or tempo) on psychophysiological recovery after different workloads of exercise for future studies.

Limitations in the present study was that parts of female participants were not able to maintain pedalling rate at $60 \mathrm{rpm}$ and the target $\mathrm{HR}$ at $80 \% \mathrm{HR}_{\text {reserve }}$ throughout the 10-min cycling exercise. The fluctuation of HR responses and pedalling rate of cycling exercise may impact the post-exercise recovery of the autonomic nervous system to some extent. The initial physical conditions in female participants could potentially underestimate or overestimate the recovery capacities in gender difference.

\section{Conclusions}

In conclusion, self-selected music intervention can improve HRR after submaximal intensity of cycling exercise in healthy female adults. In addition, a self-selected music intervention during submaximal intensity of stationary cycling exercise could reduce post-exercise anxiety in healthy male and female adults. Listen preferable music while exercise provides positive benefits on psychometric responses after submaximal intensity of cycling.

Acknowledgments: The authors would like to thank all the participants who volunteered for this study.

Conflicts of Interest: We certify that no party has a direct interest in the results of the present research.

\section{References}

Atkinson, G., Wilson, D., \& Eubank, M. (2004). Effects of music on work-rate distribution during a cycling time trial. International Journal of Sports Medicine, 25(8), 611-615.

Ballmann, C. G., Maynard, D. J., Lafoon, Z. N., Marshall, M. R., Williams, T. D., \& Rogers, R. R. (2019). Effects of listening to preferred versus non-preferred music on repeated wingate anaerobic test performance. Sports (Basel), 7(8), 185.

Bigliassi, M. (2015). Use the brain: complementary methods to analyse the effects of motivational music. Frontiers in Human Neuroscience, 9, 508.

Bigliassi, M., Karageorghis, C. I., Bishop, D. T., Nowicky, A. V., \& Wright, M. J. (2018). Cerebral effects of music during isometric exercise: An fMRI study. International Journal of Psychophysiology, 133, 131-139.

Borg, G. A. (1982). Psychophysical bases of perceived exertion. Medicine \& Science in Sports \& Exercise, 14(5), 377-381.

Chtourou, H., Jarraya, M., Aloui, A., Hammouda, O., \& Souissi, N. (2012). The effects of music during warm-up on anaerobic performances of young sprinters. Science \& Sports, 27(6), e85-e88. 
Eliakim, M., Bodner, E., Eliakim, A., Nemet, D., \& Meckel, Y. (2012). Effect of motivational music on lactate levels during recovery from intense exercise. Journal of Strength and Conditioning Research, 26(1), 80-86.

Eliakim, M., Bodner, E., Meckel, Y., Nemet, D., \& Eliakim, A. (2013). Effect of rhythm on the recovery from intense exercise. Journal of Strength and Conditioning Research, 27(4), 1019-1024.

Jarraya, M., Chtourou, H., Aloui, A., Hammouda, O., Chamari, K., Chaouachi, A., \& Souissi, N. (2012). The effects of music on high-intensity short-term exercise in well trained athletes. Asian Journal of Sports Medicine, 3(4), 233-238.

Jia, T., Ogawa, Y., Miura, M., Ito, O., \& Kohzuki M. (2016). Music attenuated a decrease in parasympathetic nervous system activity after exercise. PLoS one 11:e0148648.

Jones, L., Tiller, N. B., \& Karageorghis, C. I. (2017). Psychophysiological effects of music on acute recovery from high-intensity interval training. Physiology \& Behavior, 170, 106-114.

Lee, S., \& Kimmerly, D. S. (2016). Influence of music on maximal self-paced running performance and passive post-exercise recovery rate. The Journal of Sports Medicine and Physical Fitness, 56(1-2), 39-48.

Karageorghis, C. I., Terry, P. C., \& Lane, A. M. (1999). Development and initial validation of an instrument to assess the motivational qualities of music in exercise and sport: the Brunel Music Rating Inventory. Journal of Sports Sciences, 17(9), 713-724.

Karageorghis, C. I., \& Priest, D.-L. (2012a). Music in the exercise domain: a review and synthesis (Part I). International Review of Sport and Exercise Psychology, 5(1), 44-66.

Karageorghis, C. I., \& Priest, D.-L. (2012b). Music in the exercise domain: a review and synthesis (Part II). International Review of Sport and Exercise Psychology, 5(1), 67-84.

Karageorghis, C. I., Bruce, A. C., Pottratz, S. T., Stevens, R. C., Bigliassi, M., \& Hamer, M. (2018). Psychological and psychophysiological effects of recuperative music postexercise. Medicine and Science in Sports and Exercise, 50(4), 739-746.

Karvonen, M., J., Kentala, E., \& Mustala, O. (1957). The effects of training on heart rate; a longitudinal study. Annales Medicinae Experimentalis et Biologiae Fenniae, 35, 307-315.

Koelsch, S., \& Jäncke, L. (2015). Music and the heart. European Heart Journal, 36(44), 3043-3049.

Krout, R. E. (2007). Music listening to facilitate relaxation and promote wellness: Integrated aspects of our neurophysiological responses to music. The Arts in Psychotherapy, 34(2), 134-141.

Kudielka, B. M., Buske-Kirschbaum, A., Hellhammer, D. H., \& Kirschbaum, C. (2004). Differential heart rate reactivity and recovery after psychosocial stress (TSST) in healthy children, younger adults, and elderly adults: The impact of age and gender. International Journal of Behavioral Medicine, 11(2), 116-121.

Maddigan, M. E., Sullivan, K. M., Halperin, I., Basset, F. A., \& Behm, D. G. (2019). High tempo music prolongs high intensity exercise. Peer J. 6:e6164.

Michael, S., Jay, O., Halaki, M., Graham, K., \& Davis, G. M. (2016). Submaximal exercise intensity modulates acute post-exercise heart rate variability. European Journal of Applied Physiology, 116(4), 697-706.

Plews, D. J., Laursen, P. B., Stanley, J., Kilding, A. E., \& Buchheit, M. (2013). Training adaptation and heart rate variability in elite endurance athletes: Opening the door to effective monitoring. Sports Medicine, 43(9), 773-781. 
Savitha, D., Mallikarjuna, R. N., \& Rao, C. (2010). Effect of different musical tempo on post-exercise recovery in young adults. Indian Journal of Physiology and Pharmacology, 54(1), 32-36.

Smirmaul, B., Dos Santos, R., \& Da Silva Neto, L. (2015). Pre-task music improves swimming performance. The Journal of Sports Medicine and Physical Fitness, 55(12), 1445-1451.

Smirmaul, B. (2017). Effect of pre-task music on sports or exercise performance. The Journal of Sports Medicine and Physical Fitness, 57(7-8), 976-984.

Spielberger, C. D., Gorsuch, R. L., \& Lushene, R. E. (1970). Manual for the State-Trait Anxiety Inventory. Polo Alto, CA: Consulting Psychologists Press.

Stork, M., MY, K., Gibala, M., \& Martin, G. K. (2015). Music enhances performance and perceived enjoyment of sprint interval exercise. Medicine \& Science in Sports \& Exercise, 47(5), 1052-1060.

Terry, P. C., Karageorghis, C. I., Saha, A. M., \& D'Auria, S. (2012). Effects of synchronous music on treadmill running among elite triathletes. Journal of Science and Medicine in Sport, 15(1), $52-57$.

Urakawa, K., \& Yokoyama, K. (2005). Music can enhance exercise-induced sympathetic dominancy assessed by heart rate variability. The Tohoku Journal of Experimental Medicine, 206(3), 213-218.

(C) 2020 by the authors. Submitted for possible open access publication under the terms and conditions of the Creative Commons Attribution (CC BY) license (http://creativecommons.org/licenses/by/4.0/). 